\title{
A comparison of folate status in women of child- bearing age in Korea and in the United States
}

\author{
This article was published in the following Dove Press journal: \\ Nutrition and Dietary Supplements \\ II July 2012 \\ Number of times this article has been viewed
}

\author{
Taisun Hyun' \\ Suguna Badiga ${ }^{2}$ \\ Han Byul Jang' \\ Young-Hee Han' \\ Chandrika J Piyathilake ${ }^{2}$ \\ 'Department of Food and Nutrition, \\ Chungbuk National University, \\ Cheongju, Korea; ${ }^{2}$ Department of \\ Nutrition Sciences, University of \\ Alabama at Birmingham, \\ Birmingham, AL, USA
}

Background: Even though several studies have demonstrated that periconceptional supplementation with folic acid (FA) reduces the occurrence of neural tube defects, FA fortification has been a topic of intense debate due to the possible adverse effects of higher folate status on several health conditions. Several countries, including Korea, have been indecisive as to whether fortification is warranted or not. It is therefore helpful for these countries to compare folate concentrations in their populations with populations exposed to mandatory FA fortification.

Purpose: To evaluate the differences in the distribution of circulating concentrations of folate in Korea and the United States (US) at different time points.

Methods: The Korean study populations consisted of women of child-bearing age recruited in 1999 and in 2009. The US study populations consisted of women of child-bearing age recruited in the post FA fortification era (2005 and 2009). Plasma and red blood cell (RBC) folate concentrations were measured using the Lactobacillus casei microbiological assay.

Results: The percentage of US women with neural tube defect-protective levels of RBC folate was significantly higher compared to Korean women in 1999 and 2009. However, in 2009, when FA supplements became readily available for Koreans, $50 \%$ of Korean women in the study achieved the neural tube defect-protective level of RBC folate; $11 \%$ of them demonstrating supraphysiologic concentrations of plasma folate. Even though FA fortification in the US resulted in more than $80 \%$ of women achieving $>400 \mathrm{ng} / \mathrm{mL}$ of RBC folate by 2009 , nearly $50 \%$ also demonstrated having supraphysiologic concentrations of plasma folate, which prompted some researchers to raise concerns about possible adverse effects of higher folate status on several health conditions.

Conclusion: Encouraging Korean women of reproductive age to take FA supplements and evaluating the outcome of such efforts would be worthwhile prior to implementing a populationwide mandatory FA fortification in Korea.

Keywords: folate, fortification, child-bearing age

\section{Introduction}

Folate, a water soluble B vitamin occurring naturally in fruits and vegetables, is involved in various cellular activities as a methyl donor for methylation reactions. Because of its pivotal role in cellular metabolism, folate status has been linked with several health outcomes. Several observational studies and intervention trials have demonstrated that periconceptional supplementation with folic acid (FA), a synthetic form of folate, reduces the occurrence of birth defects, especially neural tube defects (NTDs). ${ }^{1,2}$ However, in general, public health campaigns have failed to improve folate status through recommendations of FA supplements as demonstrated by a low proportion of women of child-bearing age consuming FA supplements
Correspondence: Chandrika J Piyathilake Department of Nutrition Sciences, University of Alabama at Birmingham, 1675 University Blvd, Webb 326,

Birmingham, AL 35294, USA

Tel +l 2059755398

Email piyathic@uab.edu 
periconceptionally and nearly half of this population having unplanned pregnancies. ${ }^{3}$ Fortification of foods with FA thus offered a plausible solution to these failed health campaigns, and in 1998 fortification of cereal grains with FA (140 $\mu \mathrm{g} / 100 \mathrm{~g}$ of flour) was mandated by the United States (US) Food and Drug Administration, with the main purpose of reducing the risk of NTDs by increasing folate intake in women of child-bearing age. ${ }^{4}$ Simultaneously, countries like Canada and Chile implemented mandatory FA fortification of flour. Today, nearly 60 countries have implemented the mandatory FA fortification of food, not only to reduce the prevalence of NTDs but also to possibly reduce folate deficiency associated with other poor health outcomes. ${ }^{5}$ Despite the growing list of countries that are fortifying flour with FA, and that the adverse effects associated with FA are most likely due to extra supplement use and not due to mandatory fortification, ${ }^{6}$ there are several countries - including Korea - that are in a dilemma due to the ensuing debate on the safety of population-wide exposure to higher levels of folate on health conditions other than NTDs; there is also the belief that folate intake among women is adequate and that individuals have the right not to consume supplemental FA if they so choose to do so. ${ }^{7,8}$

Since the initiation of FA fortification, National Health and Nutrition Examination Surveys in the US have documented a 1.5-3-fold increase in the circulating concentrations of folate. This has resulted in an $80 \%-90 \%$ decline in the prevalence rate of lower circulating concentrations of folate $(\leq 3 \mathrm{ng} / \mathrm{mL}$ of serum folate and $\leq 140 \mathrm{ng} / \mathrm{mL}$ for red blood cell $[\mathrm{RBC}]$ folate), particularly among women of child-bearing age, from 1988-2006 and a 19\%-27\% reduction in the prevalence of NTDs. ${ }^{9-11}$ Although the program was able to achieve its intended objective of reducing the prevalence of NTDs, the FA fortification program has been under scrutiny with regard to potential adverse effects of higher concentrations of folate on many disease conditions. Approximately $23 \%$ of the US population has been reported to have circulating concentrations of folate $>19.8 \mathrm{ng} / \mathrm{mL}$ (referred to as supraphysiologic concentrations) within 2 years of exposure to the FA fortification program. ${ }^{12}$ Higher circulating concentrations of folate have been hypothesized to mask pernicious anemia due to vitamin B12 deficiency, cause cognitive impairment in elderly subjects, reduce the efficacy of antifolate drugs used in the treatment of malaria, rheumatoid arthritis, and psoriasis, and - most importantly - to exert adverse effects on immune function and have the potential to promote cancer. ${ }^{13-16}$ Further, there have been several reports associating excess body weight with folate concentrations. ${ }^{17,18}$
Another report showed that after mandatory FA fortification, higher maternal weight was associated with increased risk of NTDs. ${ }^{19}$

Population-wide changes in folate intake may occur in the absence of FA fortification due to changes in dietary habits or the availability of supplements containing FA. Therefore, evaluation of these trends and a comparison of individuals exposed to FA fortification programs will be informative in making decisions regarding fortification of commonly used food items with FA. The authors were in a unique position to carry out a comparison of this nature due to (1) the availability of data on circulating concentrations of folate in Korean women of child-bearing age during a time period when FA supplements were rarely available, ie, 1999, ${ }^{20}$ and when FA supplements were readily available, ie, $2009 ;{ }^{21}$ and (2) the availability of folate data from a US population exposed to an FA fortification program. With this background, the main purpose of the current study was to evaluate differences in the distribution of folate concentrations in women of child-bearing age of similar age range in the US and Korea at different time points. Because the prevalence of obesity differs between Korea and US, and a likely association between obesity and folate status has been reported, another purpose of the study was to exclude the possibility that the differences in folate concentrations that were observed were due to the differences in the prevalence of obesity between the two countries.

\section{Methods}

\section{Study population}

The study populations consisted of women of child-bearing age from Korea and the US who had largely a sedentary lifestyle (Table 1). The Korean study populations consisted of students from Chungbuk National University (Cheongju, Korea) enrolled during the year $1999(n=52)$ and $2009(\mathrm{n}=90)$. The US study populations were a subset of 338 women enrolled in 2005 by a study funded by the National Cancer Institute (R01 CA105448) and a subset of 146 women enrolled by another study funded by National Cancer Institute in 2009 (R01 CA102489). All women enrolled in the US studies were diagnosed with an abnormal Pap smear but were free of biopsy-confirmed higher grade cervical intraepithelial neoplasia. Women in the Korean study were between the age range of 18-26 years who were likely to be sexually active but with unknown Pap diagnoses. In order to allow a comparison of plasma folate and RBC folate data between the study populations independent of 
Table I The descriptive statistics of the study population

\begin{tabular}{|c|c|c|c|c|c|c|c|}
\hline & \multicolumn{2}{|c|}{ Korean } & \multicolumn{2}{|c|}{ US AA } & \multicolumn{2}{|c|}{ US CA } & \multirow[t]{2}{*}{$P$ value* } \\
\hline & 1999 & 2009 & 2005 & 2009 & 2005 & 2009 & \\
\hline Participants (n) & 52 & 90 & 230 & 81 & 108 & 65 & \\
\hline Median BMI $\left(\mathrm{kg} / \mathrm{m}^{2}\right)$ & 21 & 21 & 28 & 27 & 24 & 26 & $<0.0001$ \\
\hline Median plasma folate $(\mathrm{ng} / \mathrm{mL})$ & 7.3 & 11.0 & 10.3 & 14.7 & 13.1 & 19.2 & $<0.0001$ \\
\hline Median RBC folate $(\mathrm{ng} / \mathrm{mL})$ & 319.7 & 401.0 & 517.0 & 509.4 & 608.8 & 733.2 & $<0.000$ I \\
\hline
\end{tabular}

Note: *Median test.

Abbreviations: AA, African American; BMI, body mass index; CA, Caucasian American; RBC, red blood cell; US, United States.

the effect of age on folate status, only women in the age group of 18-26 years were included in the analysis from both the Korean and US populations. While the Korean population was unexposed to FA fortification, the US study populations had been exposed to mandatory FA fortification since 1998, the year of initiation of the mandatory FA fortification program in the US. Since there are known differences in the folate status of two main ethnic groups in the US, namely, African Americans (AAs) and Caucasian Americans (CAs), ${ }^{22,23}$ separate groups by race from the two US studies have been included as follows: study conducted in 2005 included 230 AAs and 108 CAs and the study conducted in 2009 included 81 AAs and 65 CAs. Study participants were not selected at random in either the Korean or US studies. However, blood folate values reported in the study populations are similar to trends in Korea ${ }^{24,25}$ and in the US post FA fortification era. ${ }^{9}$ The study protocols were approved by the respective Institutional Review Boards.

\section{Laboratory methods}

In all study populations, fasting blood samples were collected using standard protocols, ie, a $10 \mathrm{~mL}$ sample was drawn from each subject into ethylenediaminetetraacetic acid-containing evacuated tubes. Plasma and RBC folate concentrations in all study populations were determined following $L$. casei microbiological assay protocols established in the Department of Nutrition Sciences at the University of Alabama at Birmingham (Birmingham, AL). ${ }^{26}$ The L. casei microorganism was obtained from the American Type Culture Collection (7469; Rockville, MD). FA purified by butanol extraction was used as the folate calibrator in the assay. A 96-well plate adaptation of the assay was used to measure folate. To monitor the reproducibility of the assay, two pooled samples (low and high) prepared from plasma and obtained from the American Red Cross were assayed for folate concentrations at least 30 times in order to establish the mean \pm standard deviation. This served as the basis for the quality control for the assay as determined by the Westgard "multirule" procedure. The low and high control pools were included in every plate.
The coefficient of variation of the folate microbiological assay in both laboratories (US and Korean) was $<10 \%$. All samples were stored at $-80^{\circ} \mathrm{C}$ until the measurements were completed within 3 months of sample collection.

\section{Anthropometric measurements}

Height and weight were obtained using standard protocols. The body mass index (BMI) was calculated using the height and weight measurements $\left(\mathrm{kg} / \mathrm{m}^{2}\right)$.

\section{Statistical methods}

Descriptive statistics were used to describe the study population. Differences in the BMI and circulating concentrations of folate in the study populations were tested using the median test. Differences in the distribution of women based on the plasma folate categories ( $\leq 3 \mathrm{ng} / \mathrm{mL},>3-10 \mathrm{ng} / \mathrm{mL}$, $>10-19.8 \mathrm{ng} / \mathrm{mL}$, and $>19.8 \mathrm{ng} / \mathrm{mL}$ ) and $\mathrm{RBC}$ folate categories ( $\leq 140,>140-400 \mathrm{ng} / \mathrm{mL}$, and $>400 \mathrm{ng} / \mathrm{mL}$ ) were determined using Pearson's chi-squared test. Comparisons were made between the following groups: Korean study 1999 and 2009; US study 2005 and 2009; Korean study 1999 and US study 2005; Korean study 1999 and US study 2009; Korean study 2009 and US study 2005; and Korean study 2009 and US study 2009 by race. In order to rule out the possibility that the differences in BMI may explain the differences in the distribution of the circulating concentration of folate, differences in the median plasma and RBC folate concentrations were evaluated using the median test in the Korean study populations and a subset of the US population with a BMI range similar to that of the Korean population $\left(17-32 \mathrm{~kg} / \mathrm{m}^{2}\right)$. All analyses were performed in JMP ${ }^{\circledR}$ version 9.0 (SAS Institute, Cary, NC), and were considered significant at $P<0.05$.

\section{Results}

The study population consisted of women in three ethnic groups: Koreans, US AAs, and US CAs. AA women in both US studies had a higher median BMI followed by CA and Koreans enrolled in both 1999 and 2009. The median plasma 
and $\mathrm{RBC}$ folate concentrations were statistically different in the groups by race and by year of sample collection. CA women in 2009 had higher median plasma folate concentrations compared to all other groups followed by AA women in 2009, CA women in 2005, Korean women in 2009, AA women in 2005, and Korean women in 1999. Similarly, CA women in 2009 had higher RBC folate concentrations compared to all other groups followed by CA women in 2005, AA women in 2005, AA women in 2009, Korean women in 2009, and Korean women in 1999 (Table 1).

The populations were then categorized based on the following plasma folate categories: $\leq 3 \mathrm{ng} / \mathrm{mL}$ (deficient), $>3-10 \mathrm{ng} / \mathrm{mL}$ (sufficient), $>10-19.8 \mathrm{ng} / \mathrm{mL}$ (higher), and $>19.8 \mathrm{ng} / \mathrm{mL}$ (supraphysiologic). As shown in Table 2, none of the study populations had plasma folate concentrations $\leq 3 \mathrm{ng} / \mathrm{mL}$. Statistically significant differences were observed in the distribution of Korean women in 1999 and 2009 in the different categories of plasma folate concentrations (Table 2). While $83 \%$ and $17 \%$ of the Korean women in 1999 had plasma folate concentrations of $>3-10 \mathrm{ng} / \mathrm{mL}$ and $>10-19.8 \mathrm{ng} / \mathrm{mL}$, respectively, $42 \%$ and $47 \%$ of women had plasma folate concentrations of $>3-10 \mathrm{mg} / \mathrm{mL}$ and $>10-19.8$, respectively, in 2009. Further, while none of the Korean women had supraphysiologic concentrations of folate in 1999, 11\% of the women had concentrations $>19.8 \mathrm{ng} / \mathrm{mL}$ in 2009. An increasing trend in the percentage of women with higher plasma folate concentrations in both ethnic groups exposed to a mandatory FA fortification program between 2005 and 2009 in the US was observed. However, the percentage of Korean women with supraphysiologic concentrations of plasma folate in 2009 was higher than the percentage of US AA women in 2005.
With regard to $\mathrm{RBC}$ folate concentrations, the women were categorized based on the recommended concentrations of RBC folate required to reduce the risk of NTDs: $\leq 140 \mathrm{ng} / \mathrm{mL}$ (deficient), $>140-400 \mathrm{ng} / \mathrm{mL}$ (low), and $>400 \mathrm{ng} / \mathrm{mL}$ (sufficient). Only $2 \%$ of Korean women had deficient RBC folate concentrations in 1999. None of the other populations included in this study had deficient levels of RBC folate. Statistically significant differences were observed in the distribution of Korean women in 1999 and 2009 by RBC folate categories (Table 2). Compared to $27 \%$ of Korean women in $1999,50 \%$ had folate concentrations $>400 \mathrm{ng} / \mathrm{mL}$ in 2009 . Wide differences were also observed between RBC folate concentrations in Korean women in 1999 and AA and CA women in 2005. In contrast to $27 \%$ of Korean women, $79 \%$ of AA and $92 \%$ of CA women had RBC folate concentrations $>400 \mathrm{ng} / \mathrm{mL}$. Further, there were significant differences in the RBC folate distribution between Korean women in 2009 and AA and CA women in 2005 . While only $50 \%$ of Korean women had RBC folate concentrations $>400 \mathrm{ng} / \mathrm{mL}, 79 \%$ of AA and $92 \%$ of CA women had RBC folate concentrations $>400 \mathrm{ng} / \mathrm{mL}$. Significant differences were also observed between Korean women in 1999 and 2009 and AA and CA women in 2009. As reported in previous studies, racial differences were observed in the current study in the distribution of folate concentrations between CA and AA women, with a higher percentage of CAs having supraphysiologic concentrations of plasma folate and recommended concentrations of RBC folate compared to AAs. ${ }^{22,23}$ As shown in Table 3, it was observed that there was significant variation in the folate concentrations in women by ethnicity and by the year of sample collection within the group of Korean and US women with a BMI range of $17-32 \mathrm{~kg} / \mathrm{m}^{2}$, similar to the results observed with the entire group (Table 1).

Table 2 Comparison of the plasma and red blood cell folate concentrations of women of child-bearing age by race and the year of sample collection

\begin{tabular}{|c|c|c|c|c|c|c|}
\hline & \multicolumn{2}{|l|}{ Korean } & \multicolumn{2}{|l|}{ US AA } & \multicolumn{2}{|l|}{ US CA } \\
\hline & 1999 & 2009 & 2005 & 2009 & 2005 & 2009 \\
\hline \multicolumn{7}{|l|}{ Plasma folate } \\
\hline$\leq 3 \mathrm{ng} / \mathrm{mL}$ & 0 & 0 & 0 & 0 & 0 & 0 \\
\hline$>3-10 \mathrm{ng} / \mathrm{mL}$ & 43 (83\%) & 38 (42\%) & III (48\%) & $21(26 \%)$ & 35 (32\%) & $6(9 \%)$ \\
\hline$>10-19.8 \mathrm{ng} / \mathrm{mL}$ & $9(17 \%)$ & $42(47 \%)$ & $100(44 \%)$ & $4 \mid(51 \%)$ & 49 (45\%) & 29 (45\%) \\
\hline$>19.8 \mathrm{ng} / \mathrm{mL}$ & 0 & 10 (II\%) & $19(8 \%)$ & $19(23 \%)$ & $24(22 \%)$ & 30 (46\%) \\
\hline \multicolumn{7}{|l|}{ RBC folate } \\
\hline$\leq 140 \mathrm{ng} / \mathrm{mL}$ & I (2\%) & 0 & 0 & 0 & 0 & 0 \\
\hline$>140-400 \mathrm{ng} / \mathrm{mL}$ & 37 (7।\%) & 45 (50\%) & 49 (21\%) & 15 (19\%) & $9(8 \%)$ & $3(5 \%)$ \\
\hline$>400 \mathrm{ng} / \mathrm{mL}$ & $14(27 \%)$ & $45(50 \%)$ & I8I (79\%) & $66(81 \%)$ & 99 (92\%) & 62 (95\%) \\
\hline
\end{tabular}

Notes: $P$ value for the following comparisons is $<0.01$ for plasma and RBC folate concentration distribution: Korean women in 1999 and 2009 , AA women and CA women in 2005, AA women and CA women in 2009, Korean women in 1999 and AA and CA women in 2005, Korean women in 1999 and AA and CA women in 2009, Korean women in 2009 and AA women in 2005 ( $P$ value $<0.01$ only for RBC folate), Korean women in 2009 and CA women in 2005, and Korean women in 2009 and AA and CA women in 2009.

Abbreviations: AA, African American; CA, Caucasian American; RBC, red blood cell; US, United States. 
Table 3 Comparison of median concentrations of folate by race and the year of sample collection among women with a body mass index between $17-32 \mathrm{~kg} / \mathrm{m}^{2}$

\begin{tabular}{|c|c|c|c|c|c|c|c|}
\hline & \multicolumn{2}{|c|}{ Korean } & \multicolumn{2}{|c|}{ US AA } & \multicolumn{2}{|c|}{ US CA } & \multirow[t]{2}{*}{$P$ value } \\
\hline & 1999 & 2009 & 2005 & 2009 & 2005 & 2009 & \\
\hline Participants (n) & 52 & 89 & $|5|$ & 47 & 83 & 44 & \\
\hline Median plasma folate $(\mathrm{ng} / \mathrm{mL})$ & 7.3 & II.I & 9.8 & 14.7 & 12.9 & 19.8 & $<0.000$ I \\
\hline Median RBC folate (ng/mL) & 319.7 & 398.0 & 499.8 & 508.6 & 569.9 & 724.8 & $<0.0001$ \\
\hline
\end{tabular}

Note: *Median test.

Abbreviations: AA, African American; CA, Caucasian American; RBC, red blood cell; US, United States.

\section{Discussion}

Several epidemiological studies have shown that an intake of $400 \mu \mathrm{g}$ FA per day before pregnancy and during the early weeks of gestation is associated with a reduction in NTDs. ${ }^{27,28}$ An evaluation of the relationship between the risk of NTD and maternal concentrations of RBC folate have shown that the lowest category of NTD risk occurred when maternal $\mathrm{RBC}$ folate concentrations were $>400 \mathrm{ng} / \mathrm{mL}{ }^{29}$ suggesting that achieving this level of RBC folate should be the goal for individual recommendations or population-wide FA fortification programs. Many believe that achieving this protective folate concentration by dietary means alone remains a challenge among women of child-bearing age. As expected, the percentage of US women with an NTD-protective level of RBC folate was significantly higher since 2005 compared to Korean women in 1999 or 2009 and these differences were independent of the differences in BMI between Korean and US women. The present study also demonstrated that although none of the Korean women had deficient plasma folate concentrations $(\leq 3 \mathrm{ng} / \mathrm{mL})$ in $1999,73 \%$ of them had $\mathrm{RBC}$ folate concentrations below the level thought to be protective against NTDs when FA supplements were not recommended in Korea for nonpregnant women and when multivitamin supplements rarely contained FA. In 2009, when FA supplements became readily available for women of child-bearing age in Korea, $50 \%$ of women achieved the NTD-protective level of RBC folate along with $11 \%$ of women demonstrating supraphysiologic concentrations of plasma folate, similar to the percentage of US AA women (8\%) exposed to mandatory FA fortification in 2005, but likely with lower FA supplement intake. ${ }^{30}$ Even though FA fortification in the US resulted in more than $80 \%$ of women achieving $>400 \mathrm{ng} / \mathrm{mL}$ of RBC folate by 2009 , nearly $50 \%$ of US CA women by then also demonstrated supraphysiologic concentrations of plasma folate $(>45 \mathrm{nmol} / \mathrm{L}$ or $>19.8 \mathrm{ng} / \mathrm{mL}$ ), a level which prompted some researchers to raise concerns about possible adverse effects of higher folate status on several health conditions, as stated in the introduction. Supraphysiologic folate concentrations are likely to be associated with the presence of unmetabolized FA. ${ }^{31}$ Evidence suggests that unmetabolized FA found in blood after the ingestion of supplements or fortified foods may have adverse effects on folate binding proteins or transporters, ${ }^{32}$ possibly interfering with normal folate metabolism. Although it is possible that unmetabolized FA may have different effects on already initiated cancer cells compared to uninitiated cells, it is also important to understand that fortification will not only raise the concentrations of unmetabolized FA but also the concentrations of total folate in the body, which could have disease protective effects. The studies in the US did not corroborate the concern that supraphysiologic plasma folate concentrations seen in the post US FA fortification era increase the risk of precancerous lesions in the cervix in premenopausal women of child-bearing age. In fact, higher folate was associated with significantly lower risk of those lesions, especially when vitamin B12 is sufficient, demonstrating the importance of vitamin B12 in the high folate environment created by the FA fortification program. ${ }^{33}$ Because adequate numbers of women who had supraphysiologic concentrations of plasma folate and insufficient vitamin B12 were not found, it was not possible to evaluate whether cervical cancer risk may be higher in women with such a combination. The rarity of this micronutrient profile in this group of US women at higher risk of developing cervical cancer suggests that this concern may be of little public health relevance. However, studies have documented conflicting or equivocal results for the role of folate in other cancers, including neuroblastoma, ${ }^{34}$ breast cancer, ${ }^{35}$ and colorectal cancer. ${ }^{36}$ This inability to reach a consensus represents a critical issue and deserves further studies in view of the FA fortification programs that are underway in many countries, potentially exposing billions of people to higher levels of FA.

A study conducted in Korea in 2006-2007 demonstrated that serum folate concentrations were inversely associated with the risk of cervical cancer. ${ }^{24}$ The range of serum folate concentrations in the control group of this study (ie, females who had a normal Pap smear on the day of recruitment without any history of abnormal Pap smears) was $8.2-17.5 \mathrm{ng} / \mathrm{mL}$, 
a range which did not include supraphysiologic concentrations of folate. Compared to this study, higher folate levels - including supraphysiologic levels - were observed in 2009 in Korean women, possibly because the use of FA supplements may have increased with time. Another small study involving 36 healthy Korean women of child-bearing age published in 2008 observed a mean plasma folate concentration of $10.5 \mathrm{ng} / \mathrm{mL},{ }^{25}$ which is higher than the mean plasma folate concentrations of Korean women in 1999 (7.5 ng/mL) and lower than the plasma folate concentrations of Korean women in 2009 (12.5 ng/mL) from the current study, indicating a trend of increasing plasma folate concentrations. Newer studies are needed in Korea to answer whether the folate concentrations continue to increase and evaluate the effects of current folate concentrations on cancer risk (cervical and other cancers) and also to establish the proportion of women exceeding supraphysiologic concentrations of serum folate. This is an important issue since exposure to higher levels of folate during pregnancy is now thought to exert adverse effects on the offspring. For example, higher periconceptional FA intake was shown to be associated with increased risk of multiple congenital abnormalities, ${ }^{37,38}$ asthma, ${ }^{39}$ atopic dermatitis, ${ }^{40}$ and a possible increase in the prevalence of autism and other related autism spectrum disorders, including Asperger disorder, childhood degenerative disorder, and pervasive developmental disorder not otherwise specified. ${ }^{41}$

\section{Conclusion}

According to the current study, in the absence of a mandatory FA fortification program, $50 \%$ of Korean women have RBC levels which may be protective for NTDs. Therefore, even though public health campaigns have failed to improve folate status through recommendations of FA supplements in other countries, encouraging reproductive age Korean women to take FA supplements and evaluating the outcome of such efforts would be worthwhile prior to implementing a population wide mandatory FA fortification in Korea. Since a substantial increase in folate levels was observed during a 10 -year period, careful monitoring of folate levels and assessment of the reasons for increases in folate levels other than the availability of FA supplements will be required to avoid Korean women from reaching supraphysiologic concentrations of folate, especially if Korea decides to implement an FA fortification program. Because of the well-described limitations in the food composition tables in Korea, ${ }^{7}$ no attempt was made to compare folate intake levels between US and Korean women. Careful evaluation of folate status of Korean women of child-bearing age using improved food composition tables is warranted in future studies to establish the folate status in this population. It may also be necessary to monitor vitamin B12 levels since an imbalance created between the two micronutrients (higher folate and lower vitamin B12) during pregnancy has been associated with intrauterine programming predisposing to a common metabolic disorder seen worldwide, namely, insulin resistance. ${ }^{42}$ Finally, Koreans are unlikely to be as racially diverse as in the US, but regional differences in dietary habits or supplement use may contribute to differences in folate/vitamin B12 status, indicating the need for assessment of folate and vitamin B12 in a nationally representative sample of Korean women.

\section{Acknowledgments}

The authors acknowledge the Fulbright Senior Scholar Research Grant administered via the Korean-American Educational Commission (2012, Chungbuk National University). This work was partially supported by a research grant from the Chungbuk National University and by R01 CA105448 and R01 CA102489 funded by the National Cancer Institute.

\section{Disclosure}

The authors report no conflicts of interest in this work.

\section{References}

1. Werler MM, Shapiro S, Mitchell AA. Periconceptual folic acid exposure and risk of occurrent neural tube defects. JAMA. 1993;269(10):1257-1261.

2. Pitkin RM. Folate and neural tube defects. Am J Clin Nutr. 2007;85(1): 285S-288S.

3. Centers for Disease Control and Prevention. Knowledge and use of folic acid by women of childbearing age - United States, 1995 and 1998. MMWR Morb Mortal Wkly Rep. 1999;48(16):325-327.

4. Food and Drug Administration. Food standards: amendment of standards of identity for enriched grain products to require addition of folic acid. Final rule. 21 CFR Parts 136, 137, and 139. Fed Regist. 1996;61:8781-8807.

5. Flour Fortification Initiative. Country data: FFI database. 2010. Available from: http://www.sph.emory.edu/wheatflour/countrydata. php. Accessed March 16, 2012.

6. Berry RJ, Bailey L, Mulinare J, Bower C; Folic Acid Working Group. Fortification of flour with folic acid. Food Nutr Bull. 2010;31(Suppl 1): S22-S35.

7. Lindzon G, O'Connor DL. Folate during reproduction: the Canadian experience with folic acid fortification. Nutr Res Pract. 2007;1(3): 163-174.

8. Crider KS, Bailey LB, Berry RJ. Folic acid food fortification - its history, effect, concerns, and future directions. Nutrients. 2011;3(3):370-384.

9. McDowell MA, Lacher DA, Pfeiffer CM, et al. Blood folate levels: the latest NHANES results. NCHS Data Brief. 2008;6:1-8.

10. Honein MA, Paulozzi LJ, Mathews TJ, Erickson JD, Wong LY. Impact of folic acid fortification of the US food supply on the occurrence of neural tube defects. JAMA. 2001;285(23):2981-2986. 
11. Centers for Disease Control and Prevention. Spina bifida and anencephaly before and after folic acid mandate - United States, 1995-1996 and 1999-2000. MMWR Morb Mortal Wkly Rep. 2004;53(17):362-365.

12. Pfeiffer CM, Caudill SP, Gunter EW, Osterloh J, Sampson EJ. Biochemical indicators of B vitamin status in the US population after folic acid fortification: results from the National Health and Nutrition Examination Survey 1999-2000. Am J Clin Nutr. 2005;82(2): 442-450.

13. Troen AM, Mitchell B, Sorensen B, et al. Unmetabolized folic acid in plasma is associated with reduced natural killer cell cytotoxicity among postmenopausal women. J Nutr. 2006;136(1):189-194.

14. Smith AD, Kim YI, Refsum H. Is folate good for everyone? Am J Clin Nutr. 2008;87(3):517-533.

15. Ulrich CM, Potter JD. Folate supplementation: too much of a good thing? Cancer Epidemiol Biomarkers Prev. 2006;15(2):189-193.

16. Morris MS, Jacques PF, Rosenberg IH, Selhub J. Folate and vitamin B12 status in relation to anemia, macrocytosis, and cognitive impairment among older Americans in the age of folic acid fortification. Am J Clin Nutr. 2007;85(1):193-200.

17. Mojtabai R. Body mass index and serum folate in childbearing age women. Eur J Epidemiol. 2004;19(11):1029-1036.

18. Kimmons JE, Blanck HM, Tohill BC, Zhang J, Khan LK. Associations between body mass index and the prevalence of low micronutrient levels among US adults. Med Gen Med. 2006;8(4):59.

19. Ray JG, Wyatt PR, Vermeulen MJ, Meier C, Cole DE. Greater maternal weight and the ongoing risk of neural tube defects after folic acid flour fortification. Obstet Gynecol. 2005;105(2):261-265.

20. Hyun TS. A study on the characteristics of vitamin and mineral supplement products in Korea. J Hum Ecol. 1996;3:49-58.

21. Korea Food and Drug Administration. Information on health functional food. Updated 2012. Available from: http://hfoodi.kfda.go.kr. Accessed May 23, 2012.

22. Centers for Disease Control and Prevention. Folate status in women of childbearing age, by race/ethnicity - United States, 1999-2000. MMWR Morb Mortal Wkly Rep. 2002;51(36):808-810.

23. Dowd JB, Aiello AE. Did national folic acid fortification reduce socioeconomic and racial disparities in folate status in the US? Int $J$ Epidemiol. 2008;37(5):1059-1066.

24. Tong SY, Kim MK, Lee JK, et al. Common polymorphisms in methylenetetrahydrofolate reductase gene are associated with risks of cervical intraepithelial neoplasia and cervical cancer in women with low serum folate and vitamin B12. Cancer Causes Control. 2011;22(1):63-72.

25. Kim HA, Lim HS. Dietary folate intake, blood folate status, and urinary folate catabolite excretion in Korean women of childbearing age. J Nutr Sci Vitaminol (Tokyo). 2008;54(4):291-297.

26. Piyathilake CJ, Macaluso M, Hine RJ, Richards EW, Krumdieck CL. Local and systemic effects of cigarette smoking on folate and vitamin B-12. Am J Clin Nutr. 1994;60(4):559-566.

27. Mulinare J, Cordero JF, Erickson JD, Berry RJ. Periconceptional use of multivitamins and the occurrence of neural tube defects. JAMA. 1988;260(21):3141-3145.
28. Milunsky A, Jick H, Jick SS, et al. Multivitamin/folic acid supplementation in early pregnancy reduces the prevalence of neural tube defects. JAMA. 1989;262(20):2847-2852.

29. Daly LE, Kirke PN, Molloy A, Weir DG, Scott JM. Folate levels and neural tube defects. Implications for prevention. JAMA. 1995;274(21): 1698-1702.

30. Yang QH, Carter HK, Mulinare J, Berry RJ, Friedman JM, Erickson JD. Race-ethnicity differences in folic acid intake in women of childbearing age in the United States after folic acid fortification: findings from the National Health and Nutrition Examination Survey, 2001-2002. Am J Clin Nutr. 2007;85(5):1409-1416.

31. Pfeiffer CM, Fazili Z, McCoy L, Zhang M, Gunter EW. Determination of folate vitamers in human serum by stable-isotope-dilution tandem mass spectrometry and comparison with radioassay and microbiologic assay. Clin Chem. 2004;50(2):423-432.

32. Ashokkumar B, Mohammed ZM, Vaziri ND, Said HM. Effect of folate oversupplementation on folate uptake by human intestinal and renal epithelial cells. Am J Clin Nutr. 2007;86(1):159-166.

33. Piyathilake CJ, Macaluso M, Alvarez RD, Bell WC, Heimburger DC, Partridge EE. Lower risk of cervical intraepithelial neoplasia in women with high plasma folate and sufficient vitamin B12 in the post-folic acid fortification era. Cancer Prev Res (Phila). 2009;2(7):658-664.

34. French AE, Grant R, Weitzman S, et al. Folic acid food fortification is associated with a decline in neuroblastoma. Clin Pharmacol Ther. 2003;74(3):288-294.

35. Maruti SS, Ulrich CM, White E. Folate and one-carbon metabolism nutrients from supplements and diet in relation to breast cancer risk. Am J Clin Nutr. 2009;89(2):624-633.

36. Mason JB, Dickstein A, Jacques PF, et al. A temporal association between folic acid fortification and an increase in colorectal cancer rates may be illuminating important biological principles: a hypothesis. Cancer Epidemiol Biomarkers Prev. 2007;16(7):1325-1329.

37. Shaw GM, Croen LA, Todoroff K, Tolarova MM. Periconceptional intake of vitamin supplements and risk of multiple congenital anomalies. Am J Med Genet. 2000;93(3):188-193.

38. Yuskiv N, Honein MA, Moore CA. Reported multivitamin consumption and the occurrence of multiple congenital anomalies. Am J Med Genet. 2005;136(1):1-7.

39. Whitrow MJ, Moore VM, Rumbold AR, Davies MJ. Effect of supplemental folic acid in pregnancy on childhood asthma: a prospective birth cohort study. Am J Epidemiol. 2009;170(12):1486-1493.

40. Kiefte-de Jong JC, Timmermans S, Jaddoe VW, et al. Folate and vitamin B-12 concentrations in women during pregnancy are associated with increased prevalence of atopic dermatitis in their offspring. J Nutr. 2012;142(4):731-738.

41. Rogers EJ. Has enhanced folate status during pregnancy altered natural selection and possibly autism prevalence? A closer look at a possible link. Med Hypotheses. 2008;71(3):406-410.

42. Yajnik CS, Deshpande SS, Jackson AA, et al. Vitamin B12 and folate concentrations during pregnancy and insulin resistance in the offspring: the Pune Maternal Nutrition Study. Diabetologia. 2008;51(1) 29-38.
Nutrition and Dietary Supplements

\section{Publish your work in this journal}

Nutrition and Dietary Supplements is an international, peer-reviewed, open access journal focusing on research into nutritional requirements in health and disease, impact on metabolism and the identification and optimal use of dietary strategies and supplements necessary for normal growth and development. The journal welcomes papers covering

\section{Dovepress}

original research, basic science, clinical \& epidemiological studies, reviews and evaluations, guidelines, expert opinion and commentary, case reports and extended reports. The manuscript management system is completely online and includes a very quick and fair peer-review system, which is all easy to use. 